\title{
Estrutura, ultraestrutura e morfometria da aorta de paca (Cuniculus paca, Linnaeus, 1766) criada em cativeiro
}

\author{
[Structure, ultrastructure and morphometry of the aorta in the paca (Cuniculus paca, Linnaeus, 1766) \\ raised in captivity]
}

\author{
S.P. Garcia Filho, L.L. Martins, A.C.G. Reis, M.R. Pacheco, M.R.F. Machado ${ }^{1}$
}

Universidade Estadual Julio de Mesquita Filho - Campus Jaboticabal, SP

\begin{abstract}
RESUMO
Descreveram-se a morfologia, morfometria e ultraestrutura de segmentos das porções torácica e abdominal da aorta de quatro pacas (Cuniculus paca) adultas. Os segmentos aórticos foram analisados à microscopia de luz e à microscopia eletrônica de varredura. Mensuraram-se as espessuras do complexo formado pelas túnicas íntima e média, além da túnica adventícia. Os valores referentes à espessura do complexo formado pelas túnicas íntima e média da aorta torácica cranial foram significativamente

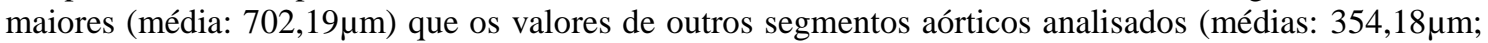
$243,55 \mu \mathrm{m})$. As camadas das paredes do vaso apresentaram variações entre si quanto à estrutura e espessura, supostamente em razão de adaptação à exigência funcional.
\end{abstract}

Palavras-chave: paca, roedor, histologia, histricomorfo, ultraestrutura

\begin{abstract}
The aim of this study was to describe the morphology, morphometry and ultrastructure of segments of thoracic and abdominal aorta portions in four male and female paca (Cuniculus paca). Parts of the segments were examined by light microscopy and part by scanning electron microscopy. Thickness measurements of the tunica intima and media complex and tunica adventitia of the aorta were taken. In all animals the thickness values for the tunica intima and media complex of the cranial thoracic aorta

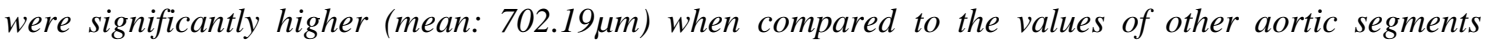
analyzed (means: $354.18 \mu \mathrm{m} ; 243.55 \mu \mathrm{m}$ ). The layers of the vessel walls show variations in structure and thickness, presumably due to an adaptation to functionaldemand.
\end{abstract}

Keywords: paca, rodent, histology, hystricomorph, ultrastructure

\section{INTRODUÇÃO}

Dentre as espécies silvestres que integram a fauna brasileira, a paca (Cuniculus paca), roedor típico de regiões tropicais, depois da capivara, é o maior da espécie no Brasil (Eisenberg e Redford, 1989). Apresenta carne de excelente qualidade, suscitando grande interesse em sua criação comercial; dessa forma, trabalhos sobre sua morfologia visam contribuir para o aproveitamento multidisciplinar desta espécie, oferecendo subsídios à sua criação racional e consequente colaboração na sua preservação
(Matamoros, 1982). A manutenção de animais silvestres em cativeiro contribui para a formação de uma importante reserva genética e oferece oportunidades para o desenvolvimento de pesquisas muitas vezes impraticáveis com os animais livres na natureza (Hutchins et al., 2003).

O sistema cardiovascular fornece e mantém o fluxo sanguíneo aos diversos tecidos do organismo de forma suficiente, contínua e variável. Constituem o sistema cardiovascular o coração, seu órgão central, e vasos sanguíneos

Recebido em 2 de março de 2011

Aceito em 12 de fevereiro de 2012

E-mail: sgarciafilho@hotmail.com 
entre os quais as artérias e veias, que se diferenciam quanto à direção centrífuga e centrípeta, respectivamente, em relação ao coração (Schummer et al., 1981; Dyce et al., 2004). A aorta torácica é o segmento que se submete, mais diretamente, à pressão sistólica (Mello, 1999) e ao fluxo turbulento do sangue impelido para a luz desse vaso pela sístole ventricular esquerda (Melbin e Detweiler, 1996).

As artérias, capilares e veias formam um sistema contínuo, revestido por endotélio ininterrupto de baixo atrito. As outras camadas de suas paredes variam amplamente na estrutura, na espessura e até mesmo na presença, em evidente ou suposta adaptação a diferentes exigências funcionais (Dyce et al., 2004) e, exceto nos capilares, a parede dos vasos é triestratificada, e seus nomes, em direção ao lúmen ou luz, são os seguintes: túnica adventícia, túnica média e túnica íntima (Dyce et al., 2004; Junqueira e Carneiro, 2008).

A aorta e seus grandes ramos são chamados de artérias elásticas ou artérias de grande calibre, sua túnica íntima é a mais interna e apresenta uma camada de células endoteliais apoiada em tecido conjuntivo frouxo e uma camada subendotelial, que pode conter, ocasionalmente, células musculares lisas. Está separada da média por uma lâmina elástica interna, componente mais externo da íntima. Essa lâmina, composta principalmente de elastina, possui fenestras que permitem a difusão de substâncias para nutrir células situadas mais profundamente na parede do vaso. Como resultado da ausência de pressão sanguínea e da contração do vaso por ocasião da morte, a lâmina elástica interna das artérias geralmente apresenta um aspecto ondulado nos cortes histológicos (Dellmann e Brown, 1982; Junqueira e Carneiro, 2008).

A túnica média é constituída, principalmente, por camadas concêntricas de células musculares lisas organizadas helicoidalmente. Interpostas entre as células musculares lisas existem quantidades variáveis de fibras e lamelas elásticas, fibras reticulares (colágeno), proteoglicanas e glicoproteínas. As células musculares lisas são as responsáveis pela produção destas moléculas da matriz extracelular. A túnica média possui uma lâmina elástica externa mais delgada que a separa da túnica adventícia. Salienta-se, que nas grandes artérias, a quantidade de lâminas elásticas na túnica média oferece a esta camada a importante função de regularizar o fluxo sanguíneo (Junqueira e Carneiro, 2008). Segundo esses autores, a túnica adventícia consiste principalmente em colágeno e fibras elásticas, e torna-se gradualmente contínua com o tecido conjuntivo do órgão pelo qual passa o vaso sanguíneo. Também são encontrados, nesta túnica, capilares linfáticos, vasa vasorum (vaso dos vasos) e nervos, podendo estas estruturas penetrar até a porção mais externa da média.

Verifica-se, na literatura especializada, destaque ao componente elástico da parede arterial (lamelas de elastina), além de outros constituintes, como o colágeno e o músculo liso, que formam um sistema mioelástico (Mello, 1999), o qual apresenta papel morfofuncional na viscoelasticidade da parede desse vaso (Wolinsky e Glagov, 1967; Dingemans et al., 1981; Clark e Glagov, 1985; Davis, 1993; Sthebens, 1996; Mello, 1999).

A histologia aórtica do rato albino foi enfocada comparativamente com a estrutura microscópica da aorta de cobaia (Mello, 1999; Mello et al., 2004), e os autores concluíram que o segmento abdominal aórtico, nestes roedores, apresenta os menores valores numéricos médios de lamelas elásticas na parede vascular, além de menor calibre vascular e um padrão estrutural mural misto, do tipo mioelástico, ao passo que, nos segmentos precedentes, observou-se padrão basicamente elástico na construção da parede aórtica. Dados similares foram encontrados em aortas de coelho (Viegas et al., 2001) e de cão (Haas et al., 1991; Orsi et al., 2004).

Considerando-se os fatores vasculares hemodinâmicos, a ocorrência de certo adelgaçamento da parede vascular aórtica, em seu curso abdominal, seria compensada por pequena diminuição, porém relevante, da pressão arterial a este nível (Guyton, 1981).

Em estudo sobre as características estruturais da aorta de coelho, mediante análise de segmentos aórticos torácicos e abdominais, verificaram-se variações morfométricas no diâmetro vascular e na espessura das camadas deste vaso, sendo os maiores valores obtidos para a porção ascendente torácica. Também observaram como características estruturais da parede vascular: presença de pregas na túnica íntima, formação de 
conexões mioelásticas na túnica média e variável número de lamelas elásticas nos distintos segmentos, sendo maior nas porções torácicas, ascendente e descendente, em relação à porção abdominal. Na túnica adventícia, predominaram as fibras de conjuntivo, dispostas de forma variada, constituindo uma rede (Viegas et al., 2001).

Investigando-se as peculiaridades ultraestruturais da parede da aorta de rato, constatou-se que as lamelas elásticas apareciam interpostas às fibras musculares lisas, sendo essa disposição principalmente notada na túnica média da parede vascular. Entre as fibras musculares lisas e as lamelas elásticas, ocorria ainda um interrelacionamento aparentemente estreito, feito por conexão e ancoramento entre ambos os elementos murais por meio de lamelas de colágeno. Na túnica íntima, havia algumas características marcantes, tais como a interrupção, em certos locais da parede, de continuidade da lâmina elástica interna, interrupção acompanhada por poros endoteliais, de certa extensão, suprajacentes à falha na estrutura elástica íntima (Mello et al., 2004).

Considerando-se a importância do esclarecimento das estruturas cardiovasculares nos mamíferos e a existência de grandes lacunas quanto à descrição específica de muitos dos aspectos anatômicos da paca, espécie que até o momento não teve sua morfologia amplamente estudada, objetivou-se com este trabalho descrever, nesses animais, o arranjo estrutural de segmentos das porções torácica e abdominal da aorta, mediante análise à microscopia de luz e à microscopia eletrônica de varredura, além de realizar a morfometria desses segmentos arteriais.

\section{MATERIAL E MÉTODOS}

A metodologia adotada foi aprovada pela Comissão de Ética no Uso de Animais, sob o protocolo de número 005891-09. Foram utilizadas quatro pacas adultas, excedentes do plantel de animais silvestres de criatório registrado junto ao Instituto Brasileiro do Meio Ambiente e dos Recursos Naturais Renováveis (IBAMA), como criatório de espécimes da fauna brasileira para fins científicos, número do cadastro 482508.
Para a realização da análise morfológica dos segmentos arteriais das pacas, procedeu-se ao exame à microscopia de luz e à microscopia eletrônica de varredura das seguintes regiões: aorta torácica cranial, torácica caudal e aorta abdominal. Consideraram-se: aorta torácica cranial à imediata continuação caudal do arco da aorta; porção torácica caudal da aorta à porção aórtica pouco antes de atravessar o hiato aórtico do diafragma; e aorta abdominal à porção desse vaso localizada caudalmente ao diafragma. Imediatamente após a eutanásia dos animais, foram colhidos segmentos das regiões dos vasos em questão, e essas amostras foram divididas, sendo que parte delas foi preparada para análise comparativa à microscopia de luz, e parte processada para observação à microscopia eletrônica de varredura.

O material destinado à análise à microscopia de luz foi fixado em solução de McDowell e, em seguida, processado para a inclusão em parafina plástica (Histosec $^{\circledR}-$ Merck - Brasil). As preparações histológicas foram obtidas mediante cortes semiseriados, respeitando-se intervalo de $100 \mu \mathrm{m}$ entre eles. Para a inclusão do material, foi realizada a rotina histológica convencional (Behmer et al., 1976). Os cortes foram corados com hematoxilina-eosina, tricrômio de masson, azul de toluidina e hematoxilina floxina. As preparações histológicas foram analisadas, e imagens capturadas em fotomicroscópio (Leica, DM5000 B) acoplado à câmera digital (Leica DFC300 FX), para a documentação.

Para o estudo ultraestrutural, as amostras colhidas foram fixadas em solução de glutaraldeído a $2,5 \%$ por 24 horas, lavadas em

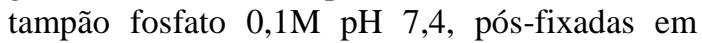
tetróxido de ósmio a $1 \%$ por duas horas, lavadas novamente em tampão fosfato, desidratadas em série crescente de álcoois (30 a 100\%), secas ao ponto crítico no aparelho EMS® 850 , metalizadas com átomos de ouro em aparelho Desk II $^{\circledR}$ (Desk II Deton Vaccun NJ, EUA) e examinadas ao microscópio eletrônico de varredura Jeol $^{\circledR}$ (Jeol@ -JSM 5410 Tokyo-Japão), operando com feixe de elétrons de $15 \mathrm{keV}$, em que algumas amostras foram documentadas.

Para a realização das análises morfométricas, foi utilizado o software de análise Leica Qwin ${ }^{\circledR} \quad$ (Leica Image Processing and Analysis Software - Leica Microsystem Ltd., 
Heerbrugg - Switzerland), sendo mensuradas as características: espessura do complexo formado pelas túnicas íntima e média e espessura da túnica adventícia.

Mediante aplicação da estatística descritiva, calcularam-se os valores das médias e dos desvios-padrão, e para o estabelecimento de comparações, aplicou-se o teste Tukey $(\mathrm{P}<0,05)$ nos valores encontrados para as túnicas da aorta.

\section{RESULTADOS E DISCUSSÃO}

Pela histoarquitetura e pelos elementos constituintes da parede da aorta da paca, tanto à microscopia de luz quanto à microscopia eletrônica de varredura, verificou-se que a estrutura geral dos vasos consistiu de camadas íntima, média e adventícia (Fig. 1), como reportado por alguns autores, em animais domésticos e em humanos (Dyce et al., 2004; Junqueira e Carneiro, 2008).

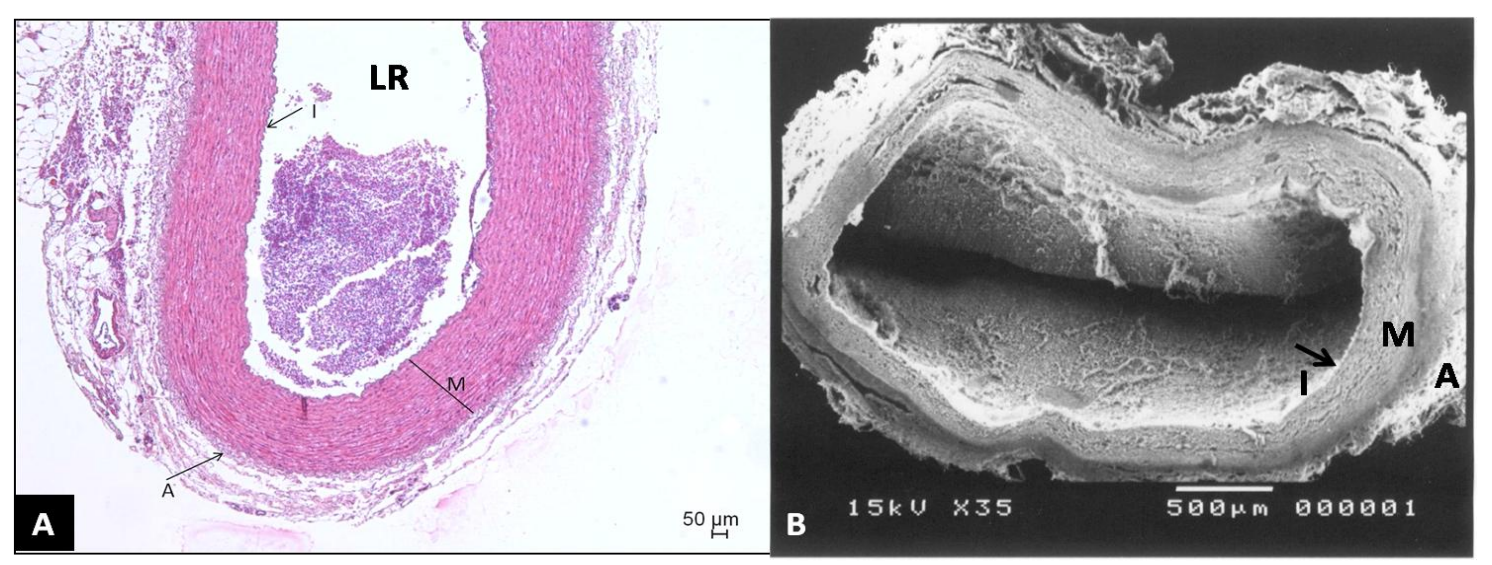

Figura 1. Paca (Cuniculus paca). A, Fotomicrografia da estrutura histológica da parede da aorta abdominal de paca adulta, evidenciando luz regular (LR) e túnicas íntima (I), média $(\mathbf{M})$ e adventícia (A); hematoxilinaeosina, 5x. B. Eletronmicrografia de varredura da artéria abdominal de paca adulta evidenciando as túnicas íntima (I), média (M) e adventícia (A).

A túnica íntima da aorta mostrou-se delgada e formada por endotélio constituído por tecido epitelial simples pavimentoso, sustentado por tecido conjuntivo frouxo (subendotélio), seguido pela membrana limitante elástica interna, esta bastante evidente (Fig. 2 e 3). Esta estrutura geral da íntima é evidente em diferentes artérias já descritas (Dellmann e Brown, 1982; Junqueira e Carneiro, 2008).

As características estruturais observadas, especialmente da túnica média, tais como fibras musculares lisas entre fibras elásticas em abundância, indicam que a aorta é tipicamente um vaso mioelástico (Fig. 2 e 3), fato que, provavelmente, refere-se ao papel da viscoelasticidade da parede desse vaso (Wolinsky e Glagov, 1967; Dingemans et al., 1981; Clark e Glagov, 1985; Davis, 1993; Sthebens, 1996; Mello, 1999). Observou-se, ainda, nessa túnica, presença da membrana limitante elástica externa, que delimita esta túnica da túnica adventícia, tal qual descrito por Junqueira e Carneiro (2008).
$\mathrm{Na}$ túnica adventícia, notou-se uma estrutura mais frouxa, constituída principalmente de fibras colágenas e elásticas. Na periferia dessa túnica, foram evidenciados, constituindo a vasa vasorum, pequenos vasos sanguíneos (Fig. 3), semelhantes aos descritos por Junqueira e Carneiro (2008).

Verificou-se, na aorta da paca, endotélio ininterrupto e variabilidade na espessura da camada adventícia e do complexo formado pelas túnicas íntima e média (Tab. 1), como relatado também em coelho (Viegas et al., 2001), em cão (Haas et al., 1991; Orsi et al., 2004), em cobaia (Mello, 1999; Mello et al., 2004) e no ratão do banhado (Resende et al., 2006). Sabe-se que as artérias são revestidas por um endotélio ininterrupto e que as camadas de suas paredes variam tanto na estrutura quanto na espessura em razão de uma suposta adaptação a diferentes exigências funcionais (Dyce et al., 2004; Mello et al., 2004). 


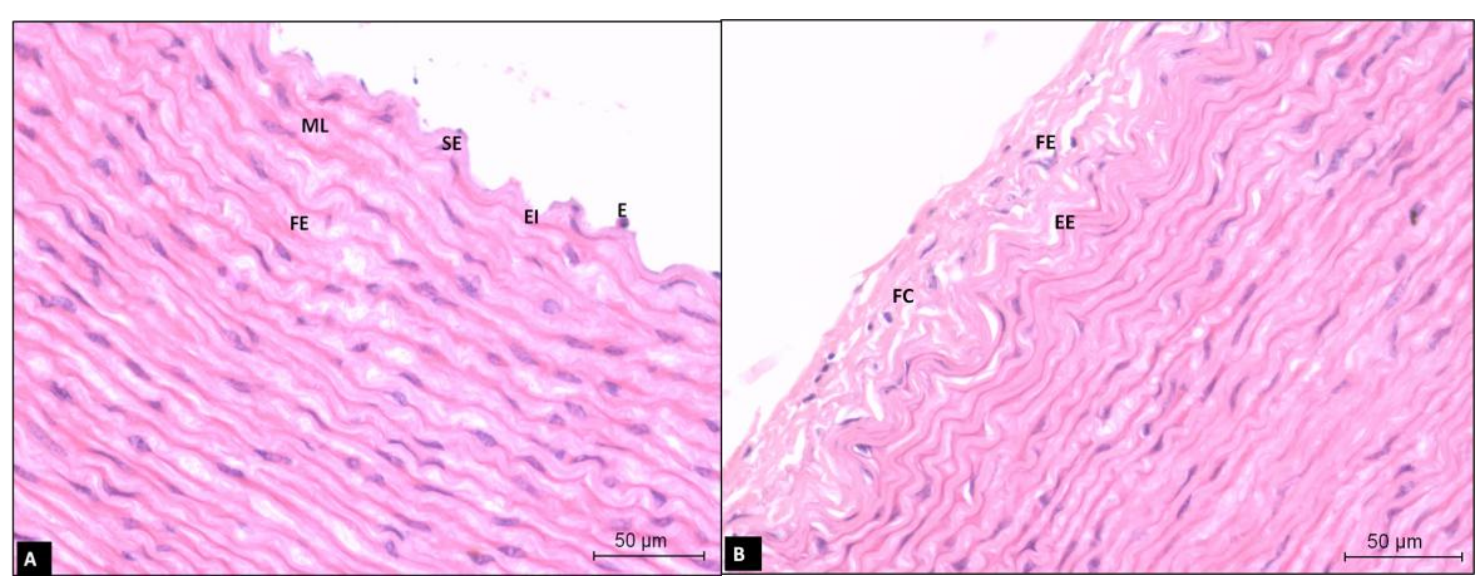

Figura 2. Paca (Cuniculus paca). A. Fotomicrografia do segmento da aorta torácica caudal de paca adulta, evidenciando, na túnica íntima, o endotélio (E), o subendotélio (SE) e a membrana limitante elástica interna (EI), e na túnica média, as fibras musculares lisas (ML) entremeadas às fibras elásticas (FE); hematoxilina-eosina, 40x. B. Fotomicrografia do segmento da aorta torácica cranial de paca adulta, evidenciando, na túnica média, a membrana limitante elástica externa (EE), e na túnica adventícia, as fibras colágenas (FC) e as fibras elásticas (FE); hematoxilina-eosina, 40x.

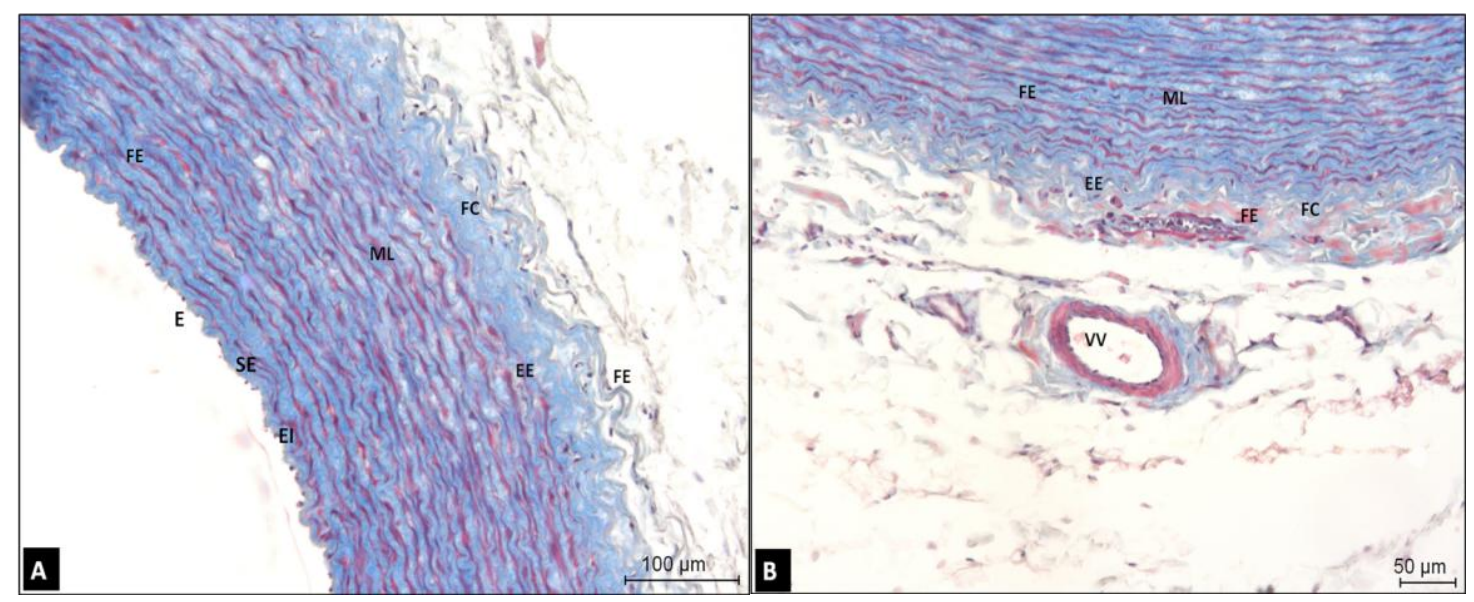

Figura 3. Paca (Cuniculus paca). A, Fotomicrografia do segmento da aorta abdominal de paca adulta, evidenciando, na túnica íntima, o endotélio (E), o subendotélio (SE) e a membrana limitante elástica interna (EI), e na túnica média, as fibras musculares lisas (ML) entremeadas às fibras elásticas (FE) e à membrana limitante elástica externa (EE), e na túnica adventícia, as fibras colágenas (FC) e as fibras elásticas (FE); tricrômio de Masson, 20x. B. Fotomicrografia do segmento da aorta torácica caudal de paca adulta, evidenciando, na túnica média, as fibras musculares lisas (ML) entremeadas às fibras elásticas (FE) e à membrana limitante elástica externa (EE), e na túnica adventícia, as fibras colágenas (FC), as fibras elásticas (FE) e a vasa vasorum (VV); tricrômio de Masson, 20x.

Quanto às comparações morfométricas das camadas vasculares arteriais da paca nos diferentes segmentos analisados, verificou-se que os valores das porções torácicas foram significativamente maiores que os das outras porções. Tal ocorrência, provavelmente, deve-se ao fato de o segmento vascular aórtico torácico submeter-se mais diretamente à pressão sistólica e a um fluxo turbulento do sangue impelido para a luz do vaso pela sístole ventricular, como descrito por Melbin e Detweiler (1996).

Presume-se que a diminuição da pressão arterial no trato abdominal (Guyton, 1981) seja responsável pelos valores significativamente menores, observados neste trabalho, para a espessura das paredes da aorta, quando comparadas aos valores dos outros segmentos arteriais. 
Tabela 1. Valores médios $(\mu \mathrm{m})$ e desvio-padrão $( \pm \mathbf{D P})$ da espessura do complexo formado pelas túnicas íntima+média e da espessura da túnica adventícia, referentes aos segmentos de aorta analisados de pacas adultas (Cuniculus paca)

\begin{tabular}{lcc} 
& $\begin{array}{c}\text { Túnica íntima }+ \text { média } \\
\text { Média } \pm \text { DP }\end{array}$ & $\begin{array}{c}\text { Túnica adventícia } \\
\text { Média } \pm \text { DP }\end{array}$ \\
\hline Aorta torácica cranial & $702,19 \mathrm{a} \pm 122,74$ & $120,70 \mathrm{a} \pm 38,79$ \\
Aorta torácica caudal & $354,18 \mathrm{~b} \pm 75,05$ & $64,98 \mathrm{~b} \pm 26,30$ \\
Aorta abdominal & $243,55 \mathrm{c} \pm 48,84$ & $77,60 \mathrm{~b} \pm 23,53$ \\
\hline
\end{tabular}

Letras distintas na coluna indicam diferenças entre os valores $(\mathrm{p}<0,05)$ pelo teste Tukey

\section{CONCLUSÃO}

Nas condições em que este experimento foi conduzido, pode-se inferir que, na paca, a espessura do complexo formado pelas túnicas íntima + média foi significativamente maior para todos os segmentos de aorta analisados. Os segmentos craniais foram os que apresentaram maior espessura de túnicas. As camadas das paredes dos vasos apresentam variações entre si quanto à estrutura e à espessura.

\section{REFERÊNCIAS}

BEHMER, O.A.; TOLOSA, E.M.C.; FREITAS NETO, A.G. Manual de técnicas para histologia normal e patológica. SãoPaulo: Edart, 1976. $115 \mathrm{p}$.

CLARK, J.M.; GLAGOV, S. Transmural organization of the arterial media: the lamellar unit revisited. Arteriosclerosis, v.5, p.19-34, 1985.

DAVIS, E. Smooth muscle cell to elastic lamina connections in developing mouse aorta. Lab. Invest., v.1, p.89-99, 1993.

DELLMANN, H.; BROWN, E.M. Histologia Veterinária. Rio de Janeiro: Guanabara Koogan, 1982. $397 \mathrm{p}$.

DINGEMANS, K.P.; JANSEN, N.; BECKER, A.E. Ultrastructure of the normal human aortic media. Virchows Arch. A: pathological anatomy and histology, Berlin, v.392, p.199-216, 1981.

DYCE, K.M.; SACK, W.O.; WENSING, C.J.G. Tratado de anatomia veterinária. 3.ed. Rio de Janeiro: Guanabara Koogan, 2004. p. 229-232.

EISENBERG, J.F.; REDFORD, K.H. Order Rodentia. In:_. Mammals of the neotropics: the northern neotropics Panama, Colombia, Venezuela, Guyana, Suriname, French Guiana. Chicago: University of Chicago, 1989. v.1, p.395-397.
GUYTON, A.C. The relationship of cardiac output and arterial pressure control. J. Am. Heart Assoc., v.64, p.1079-1088, 1981.

HAAS, K.S.; PHILLIPS, S.J.; COMEROTA, A.J. et al. The architecture of adventitial elastin in the canine infrarenal aorta. Anat. Rec., v.230, p.86-96, 1991.

HUTCHINS, M.; SMITH, B.; ALLARD, R. In defense of zoos and aquariums: the ethical basis for keeping wild animals in captivity. J. Am. Vet. Med. Assoc., v.223, p.958-966, 2003.

JUNQUEIRA, L.C.; CARNEIRO, J. Sistema circulatório. In:_. Histologia básica. 11.ed. Rio de Janeiro: Guanabara Koogan, 2008. cap. 11, p.210-218.

MATAMOROS, Y. Notas sobre la biología del tepezcuintle, Cuniculus [Agouti] paca Brisson (Rodentia: Dasyproctidae) en cautiverio. Brenesia, v.19-20, p.71-82, 1982.

MELBIN, J.; DETWEILER, D.K. Sistema cardiovascular e fluxo sanguineo. In: SWENSON, M.J.; REECE, W. (Eds.) Dukes: fisiologia dos animais domésticos. Rio de Janeiro: Guanabara Koogan, 1996. cap. 2, p. 1334.

MELLO, J.M. Estrutura da aorta e da artéria ilíaca externa de cobaia: aspectos comparativos com o rato albino e ave doméstica. 1999. 83f. (Tese. Doutorado em Anatomia) - Instituto de Biociências, Universidade Estadual Paulista, Botucatu, SP.

MELLO, J.M.; ORSI, A.M.; PADOVANI, C.R. et al. Structure of the aortic wall in the guinea pig and rat. Braz. J. Morphol. Sci., v.20, p.35-38, 2004.

ORSI, A.M.; STEFANINI, M.A.; CROCCI, A.J. et al. Some segmental features on the structure of the aortic wall of the dog. Anat. Histol. Embryol., v.33, p.131-134, 2004. 
RESENDE, H.R.A.; ALONSO, L.S.; ALVIM, N.C. et al. Aspectos histológicos da aorta do ratão do banhado (Myocastor coypus Molina, 1782). Garça, 2006. Disponível em:

<www.revista.inf.br/veterinaria07/cc/edic08cc02.pdf>. Acessado em: 6 nov. 2011.

SCHUMMER, A.; WILKENS, H.; VOLLMERHAUS, B. et al. The circulatory system, the skin and the cutaneous organs of the domestic mammals. In: NICKEL, R.; SCHUMMER, A.; SEIFERLE, E. The anatomy of the domestic animals. Berlim Hamburg: Verlag Paul Parey, 1981. v.3, p.6-7.
STHEBENS, W.E. Structural and architectural changes during arterial development and the role of hemodynamics. Acta Anat., v.157, p.261-274, 1996.

VIEGAS, K.A.S.; ORSI, A.A.; MATHEUS, S.M.M. et al. Características estructurales de la aorta de conejo (Oryctolagus cuniculus). Rev. Chil. Anat., v.19, p.131-137, 2001.

WOLINSKY, H.; GLAGOV, S.A. Lamellar unit of aortic medial structure function in mammals. Circul. Res., n.20, p.99-111, 1967. 